\title{
Fibromyalgia in patients with euthyroid Hashimoto's thyroiditis
}

Muge Bilge MD¹, Mine Adas MD², Muyesser Nergiz Yanmaz MD³, Aysen Helvaci MD

${ }^{1}$ Okmeydani Education and Research Hospital, Internal Medicine, Istanbul, Turkiye

2Okmeydani Education and Research Hospital, Endocrinology, Istanbul, Turkiye

${ }^{3}$ Okmeydani Education and Research Hospital, Rheumatology, Istanbul, Turkiye

Introduction: The aims of this study are to evaluate fibromyalgia (FM) in patients with euthyroid Hashimoto's throiditis (HT) and whether antithyroperoxidase antibody (TPOAb) positivity is associated with the FM.

Methods; We have studied 167 patients with HT and 83 healthy controls followed in our hospital. Single researcher took the history and did physical examination including manuel tender point examination according to Manuel Tender Point Survey instructions. For the diagnosis FM, 2010 American College of Rheumatology Classification Criteria for the FM was used. Thyroid assessment was done by free T4, free T3, TSH, antithyroglobulin antibody (TgAb) and TPOAb. Patients were excluded from the study if they had any other serious disease, and if there was any history of drug use that interferes with the symptoms of FM.

Results: FM was found in 40\% (67 out of 167 patients) of in HT patients, in 7\% (6 out of 83 healthy controls, $p<0,001$ ) of controls. The average age was significant higher in patients with FM than controls $(43,78 \pm 10,48$ yrs vs $40,43 \pm 10,52 \mathrm{yrs}, \mathrm{p}=0,02)$. TSH $(2,97 \pm 2,03$ vs $2,20 \pm 1,33, p=0,001)$, TPOAb $(240,92 \pm 268,6$ vs $197,05 \pm 288,14, p=0,006)$ and TgAb levels $(300,68 \pm 528,79$ vs $153,76 \pm 411,51, p=0,003)$ where notable higher in patients with FM, according to patients without FM. Widespread pain index, symptom severity scale and tender point examination showed no significant difference between the patient and control group. On the other hand widespread pain index, symptom severity scale and tender point examination showed a positive correlation with TSH $(r: 0,184, p=0,004 ; r: 0,204, p=0,001$; $r: 0,167, p=0,009$ respectively). Also TgAb showed positive correlation with symptom severity scale $(r: 0,168, p=0,02)$. Increasing age in patients with HT showed positive relationship with widespread pain index and tender point examination ( $r=0,193, p=0,012$ and $r=0,170, p=0,02$ respectively).

\begin{tabular}{|l|l|l|l|}
\hline & FS (+) $\mathbf{n = 6 7}$ & FS (-) $\mathbf{n = 1 0 0}$ & $\mathbf{p}$ \\
\hline TSH $(\mu \mathrm{IU} / \mathrm{mL})$ & $2,97 \pm 2,03$ & $2,20 \pm 1,33$ & 0,001 \\
\hline Free T4 $(\mathrm{ng} / \mathrm{dL})$ & $2,03 \pm 8,61$ & $1,09 \pm 0,36$ & NS \\
\hline Free T3 $(\mathrm{ng} / \mathrm{dL})$ & $2,99 \pm 0,48$ & $2,97 \pm 0,46$ & NS \\
\hline TPOAb $(\mathrm{IU} / \mathrm{mL})$ & $240,92 \pm 268,63$ & $197,05 \pm 288,14$ & 0,006 \\
\hline TgAb $(\mathrm{IU} / \mathrm{mL})$ & $300,68 \pm 528,79$ & $153,76 \pm 411,51$ & 0,003 \\
\hline
\end{tabular}

Conclusion: In our study, euthyroid HT patients showed significantly higher prevalence of FM, as compared to healthy control. This finding support thyroid autoimmunity may influence the development of FM, but the evidence which support that FM is related to autoimmune etiology is not clear, and FM severity may not be affected by the presence of thyroid autoantibody.

Table : Laboratory results of all participants according to presence of fibromyalgia

NS: Not Significant 